\title{
Prevention of Initial Depressive Disorders Among at-Risk Portuguese Adolescents
}

\author{
A. Paula Matos \\ M. do Rosário Pinheiro \\ José J. Costa \\ M. do Céu Salvador \\ University of Coimbra \\ Eiríkur Ö. Arnarson \\ Landspítali-University Hospital \\ W. Edward Craighead \\ Emory University
}

This study evaluated whether Arnarson and Craighead's (2009, 2011) developmentally based behavioral and cognitive program that prevented the initial episode of depressive disorders among Icelandic adolescents could be adapted to prevent depressive disorders among “at-risk" Portuguese adolescents. One hundred sixty-eight Portuguese midadolescents (primarily 14 to 15 years old), who had subsyndromal symptoms of depression but who had never met criteria for a depressive disorder, were identified by classroom screening with the CDI and subsequent K-SADS-PL interview. All 168 adolescents were offered participation in the 14-week prevention program; 70 agreed to participate in

The overall investigation was funded by a grant to APM from the FCT - Fundação para a Ciência e a Tecnologia (Portuguese Foundation for Science and Technology) with the project "Prevention of depression in Portuguese adolescents: efficacy study of an intervention with adolescents and parents" (PTDC/MHC-PCL/ 4824/2012) and the Realan Foundation, Atlanta, GA. Appreciation is expressed to Regina Plácido for her work in translating the materials into Portuguese.

Address correspondence to W. Edward Craighead, Ph.D., Department of Psychiatry \& Behavioral Sciences, Emory University, 12 Executive Park, Suite 247, Atlanta, GA 30329; e-mail: ecraigh@ emory.edu.

0005-7894/@ 2018 Association for Behavioral and Cognitive Therapies. Published by Elsevier Ltd. All rights reserved. the program, and 98 agreed to participate only in an assessment control group. Psychological disorders were evaluated at baseline, 6-, 12-, 18-, and 24-month assessments. During the 2-year follow-up period, 12 students in the assessment-only group experienced an initial depressive disorder versus 2 in the prevention group. Survival analyses indicated a significantly lower rate of initial episodes of depressive disorders, $\chi^{2}(1)=4.261, p=.039$, among the prevention group participants compared to the assessment only comparison group. The hazard ratio was .207 , and the NNT was 11. Survival analyses indicated no significant differences between the prevention condition and the assessment only condition in the occurrence of other psychiatric disorders, $\chi^{2}(1)=1.080, p=.299$. The findings indicate the program can be successfully adapted for use in Portuguese schools, and they provide a preliminary indication that those "at-risk" adolescents who chose to participate in the program, compared to those who chose to participate only in the assessments, developed fewer initial episodes of depressive disorders over the course of 24 months. The program effects were similar to the outcomes of the prior study of this program in Iceland. As in the Icelandic version of the program, its effects appeared to be specific to the depressive disorders for which the program was designed.

Keywords: depression prevention; dysthymia; Portuguese adolescents; indicated prevention; school-based prevention program 
DESPITE THE WIDESPREAD KNOWLEDGE of the prevalence of depression and the development of efficacious acute treatments, mood disorders remain the most burdensome of psychiatric disorders enormously affecting one's quality of life (Ferrari et al., 2013; Twenge, Joiner, Rogers, \& Martin, 2018). Major depressive disorder (MDD) is increasingly likely to reoccur following each episode, and dysthymia is a chronic, persistent mood disorder. The lifetime prevalence of MDD is approximately $17 \%$ (Kessler, Chiu, Demler, Merikangas, \& Walters, 2005), and MDD is now the second leading cause of disability worldwide (Ferrari et al., 2013). Although the initial mood disorder episode can occur during early childhood, the prevalence of depressive disorders increases rapidly from about $2 \%$ of the population having been depressed by age 14 to approximately $15 \%$ by age 18 , placing these adolescents at great risk for future diagnoses of psychiatric disorders (Hankin et al., 1998: McLeod, Horwood, \& Fergusson, 2016; Pettit, Hartley, Lewinsohn, Seeley, $\&$ Klein, 2013). It is also during early adolescence that the ratio of depressed females to males increases to about $2: 1$, and this ratio varies only very slightly in adulthood (Salk, Hyde, \& Abramson, 2017).

Mood disorders are associated with increased substance abuse and social dysfunction (Backenstrass et al., 2006; Lewinsohn, Solomon, Seeley, \& Zeiss, 2000), poor academic performance (Jaycox et al., 2009), cigarette smoking (Weinberger et al., 2017), increased sensitivity to life stress (Pettit et al., 2013), and increased use of medical services (Keenan-Miller, Hammen, \& Brennan, 2007). MDD appears to forestall the development of "normative" patterns of neural connectivity and is associated with abnormal cortical structures in adolescence (Casey, Jones, \& Hare, 2008; Giedd et al., 1999; Schmaal et al., 2017). Life events, especially trauma, may interact with the genome resulting in genetic expression that gives rise to chronic, recurrent lifetime patterns of depressive disorders (Nelson, Klumparendt, Doebler, $\&$ Ehring, 2017). Finally, the rate of suicide, having recently increased substantially (Curtin, Warner, \& Hedegaard, 2016), is greatest among individuals diagnosed with mood disorders. Therefore, it is important to prevent initial episodes so individuals continue normative neural development, their social and academic skills advance at typical levels, they avoid early depression-related gene expression, and most optimistically - but possibly - they never suffer from MDD.

Not all data and their implications regarding youth depressive disorders are negative-e.g., it increasingly appears that depression may be prevented or at least forestalled, especially if neither parent of the at-risk individual suffers from a mood disorder (Garber et al., 2009). For quite some time, prevention programs have been classified as universal (all students), selected (students having some risk factors), and indicated (students having few or mild symptoms of a disorder of interest) (Craighead, Beardslee, \& Johnson, 2017). Although there are somewhat conflicting conclusions across metaanalyses, the most rigorous studies, utilizing larger sample sizes across various intervention settings, have concluded there is only marginal support for the effectiveness of universal programs, somewhat stronger support for selected programs, and the strongest support for indicated (targeted) programs (Calear \& Christensen, 2010; Merry et al., 2011; van Zoonen et al., 2014; Werner-Seidler, Perry, Calear, Newby, \& Christensen, 2017). As noted by Werner-Seidler and colleagues, when commenting on the inconsistencies among meta-analyses of prevention of depression programs, "a key difference between the current and previous reviews is that previous reviews did not distinguish between school-based and community settings. The data from the current review suggests for depression programs delivered in the school environment, targeted intervention may be more efficacious" (2017, p. 42).

As with most disorders and diseases, preventing the initial episode is the most effective way to reduce the prevalence and burden of depressive disorders. Nevertheless, the vast majority of indicated depression prevention studies have included both individuals currently or previously depressed and individuals who have never been diagnosed with depressive disorders (Craighead et al., 2017). Although prevention programs are clearly needed to reduce relapse or recurrence for those who have already suffered a depressive disorder, there are a variety of reasons why it is important to evaluate indicated prevention programs specifically designed for those who, though they may report subsyndromal depression, have never yet suffered from a clinically diagnosed depressive disorder. First, the depressive disorder causes pain and suffering for the individual, the family, and society. Second, there are psychological, social, and pathophysiogical sequelae to the first episode that may render prevention and intervention different and more complex for subsequent episodes (Klein et al., 2013). Third, mixing individuals who currently or previously suffer from a depressive disorder with those who are experiencing subsyndromal depressive symptoms may alter a prevention program's processes and outcomes, making it difficult to interpret the results of such studies. This distinction of adolescents "at-risk" and those currently or previously depressed will become increasingly important with the accrual of studies of genetic and neural biomarkers related to 
the prevention of depression. For example, the initial episode and its treatment may subsequently impact neural and genetic variables (Dunlop \& Mayberg, 2014), thereby ultimately limiting, or even precluding, the identification of those predictors of prevention of the initial episode of depressive disorders. Consequently, the currently reported study focused on the prevention among individuals "at-risk" for developing an initial episode of depressive disorders.

The primary purposes of the current study in Portugal were to adapt and evaluate the Arnarson and Craighead $(2009,2011)$ prevention project previously conducted in Iceland. The Icelandic study utilized both subsyndromal depression (Children's Depression Inventory [CDI]; Kovacs, 1992) and an explanatory style measure (Children's Attributional Style Questionnaire [CASQ]; Kaslow, Tannenbaum, \& Seligman, 1978; Seligman et al., 1984) to screen for participants because prior research had reported that both were predictors of future depression. However, when the two variables were entered simultaneously to predict future depression in the analyses of the Icelandic study, only the subsyndromal depression score predicted outcome (Arnarson \& Craighead, 2009). Because of this finding and the length of time and difficulty in completing the explanatory style measure, in the pilot work for this study and in the current study, only the CDI was employed as a screening measure of subsyndromal depression.

Rather than utilize a randomized control trial (RCT) design, in Portugal the program was evaluated in a practically useful methodology, allowing "at-risk" adolescents to choose if they would participate in the 14 -week prevention program or if they would only participate in the assessments over the 24-month period. Within this approach, factors other than the actual program might have affected the potential differential group effects, thereby limiting the scientific interpretability of the outcomes, but the results remain highly informative for interventionists wishing to implement an indicated prevention program in the school setting. This design allowed us to evaluate what would happen when students chose or did not choose to participate in an offered program, as they would do in a prevention program proffered by a school. Because the Iceland study was conducted within a homogeneous society in a small country, it was important to study the preventive effects of this program when adapted for use in a more populous and culturally heterogeneous country such as Portugal.

The presence of a parent suffering from a previous or current depression has emerged as an important factor moderating prevention program effects. For example, Garber and colleagues (2009) found their prevention program, when compared to a control group, ineffective for youth who had a depressed parent but very effective for those at-risk students who did not have a depressed parent. Thus, the current study evaluated the moderating effect of parental depression on the occurrence of an initial episode for youth at-risk (as a result of their mild depressive symptoms at the onset of the study) for developing a depressive disorder over the course of the current study. Based on the prior substantial negative impact of parental depression on the prevention of depression intervention (Garber et al., 2009), it was expected that the presence of a parent with depression would result in a lesser impact of the Portuguese program in preventing an at-risk adolescent from developing a depression during the 2-year follow-up period.

The primary aims of the present study were to adapt and evaluate the preventive effects of the Iceland prevention program (Arnarson \& Craighead, 2009 , 2011) among Portuguese adolescents who had never met criteria for a depressive disorder but were experiencing subsyndromal depressive symptoms. A secondary aim was to determine if the presence of a depressed parent in the youth's life moderated the effects of this indicated Portuguese program on the occurrence of an initial episode of depressive disorders. Another secondary aim was to evaluate whether baseline demographic and clinical variables predicted who among the at-risk adolescents would develop a depressive disorder during the 24-month follow-up period.

\section{PARTICIPANTS}

\section{Method}

Initial invitations to participate in the screening phase of this study were extended to 2,179 Portuguese adolescents in 27 different schools. Invited participants lived in Coimbra or nearby in various small cities within 110 kilometers of Coimbra in northcentral Portugal. A total of 1,371 agreed to participate in the initial screening session. These 1,371 initial participants were eighth and ninth grade Portuguese adolescents aged 13-16 (primarily 14-15; mean = 14.11; $S D=.87$ ) who completed the screening process that occurred during 2013-2014. One hundred sixty-eight (122 female; $72.6 \%$ ) of the preceding 1,371 met the initial criteria for inclusion in the project. Over a 2-year period, 98 (69 female; $70.4 \%$ ) chose to participate only in assessments at screening, baseline, and four subsequent follow-up assessments, and 70 (53 female; $75.7 \%$ ) chose to participate in screening, an initial baseline assessment, 14 weekly sessions of an intervention program, and four post-intervention follow-up assessments. According to the SES classification system of Simões 
(1995), participants were typical Portuguese adolescents with $60.1 \%$ from low SES, 31\% from medium class SES, and $8.9 \%$ from high level of SES.

Students were included if they met screening criteria for subsyndromal depression and, during a subsequent structured interview, were found to never have had a depressive episode; those with past or current depression were excluded from further participation, and their parents were notified that their child might profit from receiving mental health services. Additional exclusion criteria included anyone with a prior or current diagnosis for psychosis, ADHD, anorexia nervosa, or Bipolar I or II disorder. Pilot programs had indicated that students with ADHD and anorexia nervosa were too disruptive to allow for the program to be offered in the group setting (see also Arnarson \& Craighead, 2009).

All participants' parents completed consent forms and students completed assent forms prior to participation. Authorization for this work was approved by the Ethical Committee of the Faculty of Psychology and Educational Psychology of the University of Coimbra, the National Evaluation Committee on Ethics that regulates and supervises research conducted in school settings, and the appropriate headmasters and staff members of the schools who participated in the study.

MEASURES

Children's Depression Inventory (CDI)

The CDI is a 27-item self-report, symptom-oriented scale that rates the severity of depression during the past 2 weeks preceding the completion of the questionnaire. It is designed for children/adolescents, ages 7-17 years. Each of the 27 items comprises 3 sentences used by the student to rate the severity of the symptom. Kovacs $(1985,1992)$ and Smucker, Craighead, Craighead, and Green (1986) found this inventory had excellent internal consistency (alpha coefficients of .83 to .94). The present study utilized the total score of the Portuguese version CDI total score (Marujo, 1994), which had a Cronbach's alpha of .90. During the 2 years prior to the current study, we conducted screenings in pilot work in school settings and administered the CDI in the same fashion as in the current study. In order to identify those with subsyndromal depression, we used the $75^{\text {th }}-89^{\text {th }}$ percentiles (total CDI scores of 15-23) from these pilot samples of 1,664 (1,024 females) Portuguese adolescents ages 12 to 18 years old ( $70 \%$ of these pilot participants were ages 13-15). (See Table 1 for descriptive and demographic data.)

\section{Kiddie-SADS-Present and Lifetime Version} (K-SADS-PL)

The K-SADS-PL (Kaufman et al., 1997), developed as an interview for child and adolescent psychiatric diagnosis, was used to provide information regarding a current, previous, or lifetime psychiatric disorder. The interview comprises 82 screener items covering 22 diagnostic categories. In-depth questions are provided for each diagnosis that is positive on the screener items. Completion of the K-SADS-PL takes 30-45 minutes for individuals meeting no criteria for a psychiatric diagnosis and between $1 \frac{1 / 2}{2}$ hours to $2 \frac{1}{2}$ hours for a child or adolescent meeting criteria for a diagnosis (Kaufman et al., 1997). Reliability and validity of the interview for depressive disorders are high (Kaufman et al.). In preparation for this study, the PI and a graduate student viewed training

Table 1

Demographic and Descriptive Baseline Data

\begin{tabular}{|c|c|c|c|c|c|c|c|c|c|}
\hline \multirow[b]{2}{*}{ Characteristic } & \multicolumn{2}{|c|}{$\begin{array}{l}\text { All At-Risk } \\
\text { Adolescents } \\
(\mathrm{N}=168)\end{array}$} & \multicolumn{2}{|c|}{$\begin{array}{l}\text { Prevention } \\
\text { Program Group } \\
(\mathrm{N}=70)\end{array}$} & \multicolumn{2}{|c|}{$\begin{array}{l}\text { Control Group } \\
(\mathrm{N}=98)\end{array}$} & \multirow[b]{2}{*}{$t$} & \multirow[b]{2}{*}{ df } & \multirow[b]{2}{*}{$\mathrm{p}$} \\
\hline & Mean & SD & Mean & SD & Mean & SD & & & \\
\hline Age (years) & 14.11 & 0.87 & 14.06 & 0.88 & 14.14 & 0.87 & -0.637 & 165 & 0.525 \\
\hline \multicolumn{10}{|l|}{ Measure } \\
\hline CDI & 14.96 & 5.41 & 14.69 & 5.11 & 15.16 & 5.64 & -0.563 & 167 & 0.287 \\
\hline \multirow[t]{2}{*}{ MASC Total } & 1.34 & .41 & 1.31 & .39 & 1.37 & .42 & -0.952 & 167 & 0.171 \\
\hline & $\mathrm{N}$ & $\%$ & $\mathrm{~N}$ & $\%$ & $\mathrm{~N}$ & $\%$ & $x^{2}$ & df & $\mathrm{p}$ \\
\hline \multicolumn{10}{|l|}{ Sex } \\
\hline Male & 46 & 27.4 & 17 & 24.3 & 29 & 29.6 & 0.578 & 1 & 0.447 \\
\hline Female & 122 & 72.6 & 53 & 75.7 & 69 & 70.4 & & & \\
\hline \multicolumn{10}{|c|}{ Socio-economic status } \\
\hline High & 15 & 8.9 & 1 & 1.4 & 14 & 14.3 & 13.442 & 2 & 0.001 \\
\hline Medium & 52 & 31.0 & 30 & 42.9 & 22 & 22.4 & & & \\
\hline Low & 101 & 60.1 & 39 & 55.7 & 62 & 63.3 & & & \\
\hline
\end{tabular}


tapes and interviews with patients at the Emory University Child and Adolescent Mood Program. Subsequently, interviewers conducted the K-SADSPL with 46 psychiatric outpatients comprising Portuguese youth aged 10-18; the Kappa coefficient was .79 for MDD (Marques, Matos, \& Salvador, 2018), which was very similar to the scale's original reliability data. The subjects who had qualified for potential participation based on their CDI screening scores were asked to participate in the K-SADS-PL interview. This interview provided the psychiatric diagnostic information relevant to the previously stated inclusion and exclusion criteria.

\section{Adolescent-Longitudinal Interval Follow-up Evaluation (A-LIFE)}

The A-LIFE Interview (Keller, 1993) was developed for use with adolescents based on the Longitudinal Interval Follow-up Evaluation scale (LIFE: Keller et al., 1987), a clinical interview for adults. The A-LIFE was translated, adapted, and adequate psychometric properties were found for Portuguese adolescents by Matos, Costa, Martins, and Antunes (2017). By utilizing the details provided by the interview, it is possible to calculate the onset and offset of an episode of a disorder, the duration of recovery time (the period between episodes, if any), and the time until subsequent relapse or recurrence. The interview is divided into three general sections, including psychopathology, psychosocial functioning, and general severity of the disorder (GSD). The psychopathology domain used in the current study provides information regarding whether the participant had met the criteria and symptoms of a DSM-IV disorder since the preceding K-SADS-PL or A-LIFE interview. This interview allows for evaluation of the evolution of the psychiatric disorder over a period of time between two dates, typically the preceding 6 months, although the time period can vary.

Keller and colleagues (1987) obtained high interrater reliability (.80 or higher) for most of the psychopathology disorders. Initially in this project, the PI and a graduate student visited Emory University where the staff regularly uses the A-LIFE and had been trained by Keller's colleagues; the Emory staff trained the Portuguese staff to adequate understanding and reliability of the A-LIFE by use of existing videorecorded interviews. The A-LIFE was translated into Portuguese. Further training to assure ongoing reliability was conducted at Coimbra University for 42 participants; one interviewer, whose scores were employed for diagnostic purposes, conducted videorecorded face-to-face interviews in the school, and another interviewer rated the students by viewing and rating the video recordings. The inter-rater reliability for the interviewers was acceptable $($ Kappa $=.73)$. The A-LIFE measure of greatest interest in the current study is the 6-point rating of each disorder with a relevant score of 4, 5, or 6 and impairment yielding a diagnosis of "depression" or "dysthymia"; dysthymia was diagnosed when a student experienced impaired functioning and an adequate number of symptoms persisted for 1 year.

\section{Multidimensional Anxiety Scale for Children (MASC)}

The MASC (March, Parker, Sullivan, Stallings, \& Conners, 1997) assesses symptoms of anxiety in children and adolescents. It comprises 39 items rated on a 4-point Likert scale $(0=$ never; 1 = rarely; 2 = sometimes; and 3 = often), including items comprising physical symptoms, social anxiety, harm avoidance, and separation anxiety. The MASC total score was employed in the current study. In the initial evaluation by the scale's authors (March et al., 1997), the Cronbach's alpha value (.90) was excellent. In pilot work for the current project, the MASC was translated into Portuguese, with the necessary cultural adaptations, then backtranslated by a different translator, and then compared to the original English version with discrepancies corrected by a third reviewer. During 2009-2011, a psychometric analysis of a Portuguese version of the MASC was undertaken in a schoolbased sample of 2,041 Portuguese adolescents aged 12-18 in north-central Portugal. All questionnaires were completed in a classroom setting under the supervision of a researcher. The MASC's internal consistency measured by Cronbach's alpha was .89 (Salvador et al., 2017). The same version of the Portuguese MASC was administered in the same setting to similarly aged Portuguese adolescents in the current study.

\section{Parental Depression}

At the time of the baseline interview, adolescents were asked if their parents had previously or currently suffered from depression. Students answered "yes," "no," or "I don't know." Additionally, parents reported on any depressive disorders of their own in the same format as the adolescents had answered.

\section{INTERVENTION CONDITIONS}

\section{Prevention Program Group}

The prevention program was based on the Icelandic "Thoughts and Feelings" program (see Arnarson \& Craighead, 2009) consisting of fourteen 90-minute group sessions delivered weekly in the school setting by consulting psychologists. Both the group leader and the student manuals were translated from Icelandic to English, back translated to Icelandic, and then corrected in the English version. The English 
version was then translated to Portuguese by the program staff, back translated into English, and then corrected in the final Portuguese version by a professional translator. After translation was completed, the authors, who had extensive experience with the program and working with Portuguese adolescents, met for two workshops in order to adapt the program for use with Portuguese students. The program was further culturally adapted by using Portuguese examples, posters, stories, and videos. During two previous school years, pilot programs with similarly aged Portuguese adolescents were conducted, and the cultural adaptations were discussed and modified as appropriate based on the pilot group experiences. The pilot programs were utilized to develop the specific treatment rationale presented in the current intervention program and to evaluate the quality and the cultural appropriateness of the prevention program. The steps of the program included: (a) introduction to the group; (b) presentation of the program and the topics to be covered during the program; (c) implementation of behavioral interventions, such as relaxation training and monitoring changes of activity levels; (d) cognitive interventions including thought and feelings monitoring, correcting cognitive processing errors, and explanation of relationships of thoughts, processing errors, and fundamental self-beliefs including group examples of correction of fundamental beliefs; (e) problem solving based on the Nezus' (Nezu, Nezu, \& Perri, 1989) model; and (f) review and use of program coping strategies to prevent depression.

\section{Assessment-Only Group}

The assessment-only group met the same criteria as the prevention program participants. They were all offered the opportunity to participate in the prevention program but chose not to participate in the program. Rather, they chose to only participate in the additional assessment sessions, including both the youth and the parent assessments.

\section{PROCEDURE}

The PI (A.P.M.) wrote a letter describing the project to the parents of students aged 13-16 (primarily 14-15) and in $8^{\text {th }}$ and $9^{\text {th }}$ grades of the schools. Thirteen hundred and seventy-one (878 females) agreed to participate in the project, which included a potential prevention program and six assessment sessions (a screening assessment, baseline assessment, and four subsequent assessment sessions). Three hundred forty-one students scored between the $75^{\text {th }}-89^{\text {th }}$ percentiles (raw scores of $15-23$ ) on the CDI screening and qualified for possible inclusion in the prevention program because of this reported level of subsyndromal depression. Three hundred eleven participated in the K-SADS-PL interview in order to identify those who previously or currently met criteria for MDD or dysthymia or who met other exclusion criteria.

One hundred eighty students in 27 schools met the criteria by scoring between the $75^{\text {th }}$ and $89^{\text {th }}$ percentiles from the screening session and had never been depressed or did not meet the exclusion criteria as assessed by the K-SADS-PL. Twelve participants were not offered further participation in the program because they were students in four schools where there were too few participants that met criteria and would have been qualified for the program; thus, these 12 students did not participate further in the study, but were given program T-shirts for their participation. The remaining 168 students in 23 schools were all offered the opportunity to participate in the prevention program; 98 (69 female; $70.4 \%$ ) of these 168 declined participation in the prevention program but agreed to participate in all assessments, and they, consequently, became the assessment-only group. The remaining 70 participants ( 53 female; $75.7 \%$ ) agreed to participate in the program. This design was chosen to represent the real-world response to an offer to participate in a school-based depression prevention program.

After the screening, all qualified students participated in a baseline (t1), post-intervention 6 months (t2), 12 months ( $\mathrm{t} 3$ ), 18 months (t4), and 24 months (t5) follow-up assessment sessions. The A-LIFE interviewers at times $\mathrm{t} 2-\mathrm{t} 4$ were masked regarding the intervention condition of the participant interviewed. Participants in both conditions were paid 20-30 Euros (equal across group conditions) at the t5 assessment session.

Depending on whether they were continuous or categorical data, baseline comparisons of the two groups on relevant initial measures were evaluated with t-tests or $\chi^{2}$ analyses. The effects of the program on diagnosed depressive disorders were evaluated by estimating survival curves of new episodes of depressive disorders, and rates of disorders for the 24-month data using the Cox proportional hazards model (Cox \& Oakes, 1984). Parental depression at baseline was tested as a predictor of initial depressive disorders and as a moderator of the prevention program effects. Baseline predictors of future depressive disorders were tested using simultaneous multiple regressions of depressive outcomes.

\section{Results}

At baseline (T1 assessment) the "prevention" and the "assessment" groups did not differ on age, level of depression on CDI, MASC, or gender proportions. There were no differences in the prevention 
and assessment groups among the low and medium socioeconomic levels of participants (over $90 \%$ of sample), though there were significantly more "assessment only" participants from the high socioeconomic level (less than $10 \%$ of sample) (see Table 1).

At the 24-month evaluation period, 119 of the $168(70.8 \%)$ students participated in the 24 -month follow-up evaluation; $56(80 \%)$ of the prevention program group participated in the assessment and $63(64.3 \%)$ of the assessment-only group participated in that follow-up assessment. Thirteen $(18.6 \%)$ of the prevention program participants were censored without a depressive disorder at one of the $\mathrm{t} 2-\mathrm{t} 5$ assessment periods. One prevention program participant experienced a depressive disorder prior to the 12-month ( $\mathrm{t} 3$ ) assessment and one more at the 24-month assessment (t5), yielding a total of two prevention program participants who received a depressive disorder diagnosis. Twelve of the assessment-only participants were censored without a depressive disorder at the 6-month (t2) assessment, 12 at the 12-month (t3) assessment, and 3 at the 18-month (t4) assessment. Two assessment-only participants met criteria for a depressive disorder prior to the 6-month (t2) assessment, 5 more at the 12-month (t3) assessment, 1 at the 18 -month (t4) assessment, and 4 at the 24-month (t5) assessment for a total number of 12 assessmentonly group participants experiencing a depressive disorder during the study. Both of the prevention group participants who experienced a depressive disorder were diagnosed as dysthymic, while 3 of the 12 control group participants met criteria for a dysthymic disorder, 1 met criteria for both dysthymia and major depression, and 8 met criteria for major depression.

The survival analyses indicated that significantly fewer of the prevention program participants compared to the assessment-only group participants developed an initial episode of depression or dysthymia, $\chi^{2}(1)=4.261, p=.039$. (See Figure 1.) The hazard ratio was .207 , which indicates that by 24 months those who participated in the prevention program, compared to those in the assessment-only group, had a decreased probability of $79.3 \%$ of experiencing an initial episode of depression or dysthymia; a student who participated in the prevention program was only $20.7 \%$ as likely to develop an initial episode of depression or dysthymia as a student who chose to be in the assessmentonly group (see Table 2 ). Despite $27.4 \%$ of the sample being male at the beginning of the study, except for one control group male, all diagnosed episodes of depressive disorders occurred among the female participants. The number needed to treat (NNT) was 11, which suggests that compared to the assessment-only group 11 more individuals would have to participate in the prevention program in order to prevent one more diagnosis of a depression disorder among at-risk adolescents.

Among the 70 participants in the prevention program, $19(27.1 \%)$ experienced an episode of some other psychiatric disorder during the 24-month follow-up; all 19 experienced an anxiety disorder. Seventeen of the $98(17.3 \%)$ of the assessment-only group experienced a psychiatric disorder other than depression or dysthymia, and 2 of the participants who experienced a depressive disorder also were diagnosed with a comorbid anxiety disorder. Ten of

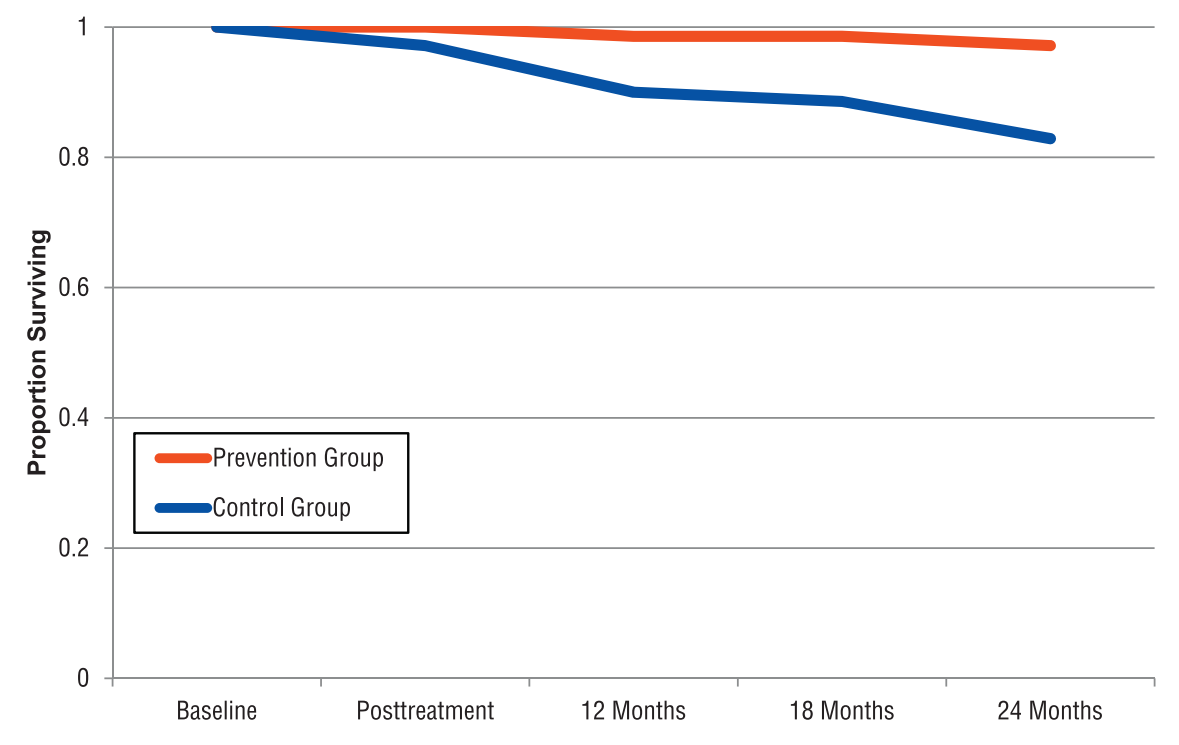

FIGURE I Cumulative proportion of participants surviving without depressive relapse/ recurrence over 24 months of follow-up 
Table 2

Cox Proportional Hazard Model

\begin{tabular}{|c|c|c|c|c|c|c|c|c|}
\hline & coef. (B) & Std. Err. (SE) & Wald & gl & $p$ & hazard ratio & $\begin{array}{l}\mathrm{Cl}_{95 \%} \\
\mathrm{~L}\end{array}$ & $\begin{array}{l}\mathrm{Cl}_{95 \%} \\
\mathrm{U}\end{array}$ \\
\hline Group & -1.577 & 0.764 & 4.261 & 1 & .039 & .207 & 0.46 & .923 \\
\hline
\end{tabular}

the assessment-only control participants experienced an anxiety disorder, one PTSD, and one OCD. The frequently comorbid disorder, ADHD, was a baseline exclusion criterion, perhaps explaining the low rate of comorbid ADHD during the course of the study. Survival analyses indicated there were no significant differences between the prevention program and the assessment-only program in the occurrence of other psychological/psychiatric disorders, $\chi 2(1)=1.080, p=.299$. The primary difference between the two groups was in the prevention group's lower rate of depressive disorders (the disorders toward which the program was directed) rather than differences in rates of any other diagnosed disorders.

In contrast to prior research, the baseline presence of a depressed parent in the adolescent's home did not predict the occurrence of an initial episode of depressive disorders during the 24 months of the program. It also failed to moderate the effects of the prevention program.

A simultaneous multiple regression model of baseline predictor variables (age, gender, socioeconomic status, initial level of depression, and initial level of anxiety) failed to predict the occurrence of an initial episode of depression disorders during the follow-up period, even though there were more participants from high SES in the assessment-only group; for this reason, these variables were not entered in the survival analyses regarding depression outcomes. The initial CDI score did not significantly predict the initial episode of depressive disorders (estimate $=.142, \mathrm{SE}=.077$, Wald $\chi^{2}=3.441, p=$ .064). However, the initial total score on the CDI did significantly (estimate $=0.147, \mathrm{SE}=.064$, Wald $\chi^{2}=$ $5.287, p=.021$ ) predict the occurrence of other nondepression diagnosis of psychopathology with higher CDI scores predicting more frequent occurrence of other psychiatric disorders. The total score on the MASC yielded a nonsignificant trend (estimate = $1.833, \mathrm{SE}=.971$, Wald $\left.\chi^{2}=3.564, p=.059\right)$ with higher scores tending to predict occurrence of nondepression psychiatric disorders.

\section{Discussion}

The current study was undertaken to determine if the effects of a program designed to prevent the initial episode of depression or dysthymia in Iceland could be extended to a culturally different country
(Portugal) in Western Europe. The program was successfully translated, and the necessary cultural adaptations were completed. Utilizing a design representative of the likely occurrence when a public school implements an indicated prevention program for adolescents "at-risk" for depression, we allowed the identified "at-risk" adolescents to choose whether or not to participate in the program. The effects of the program in preventing the initial episode of depressive disorders were quite similar to those obtained in a fully randomized trial with the same program when it had been evaluated in Iceland (Arnarson \& Craighead, 2009, 2011), and the positive impact of the program extended throughout the approximately 2 years of the follow-up period. The NNT was also quite similar to that obtained in Iceland and reported in the most rigorous meta-analyses of prevention of depression in school settings (van Zoonen et al., 2014).

One strength of the study was that after the "at-risk" youth were identified by their CDI scores, they participated in a structured clinical interview (K-SADS-PL) that provided information to determine if they had ever experienced an episode of depression or dysthymia. The K-SADS-PL also identified the presence of any disorders that met exclusion criteria. This was important because the rate of depression is at least twice as high during the 15 - to 18 -year-old period for individuals who have had a previous depressive disorder compared to those at-risk adolescents who have never suffered a previous depressive disorder; furthermore, the academic, social, health, and clinical sequelae for individuals who have experienced a depression prior to ages 14-15 are substantial (McLeod et al., 2016; Pettit et al., 2013).

A second strength of the study was that the follow-up evaluations included the A-LIFE clinical interview that covered the entire time since the previous assessment-typically 6 months. The use of the A-LIFE interview in this manner avoided the serious clinical research problem created when selfreport measures that routinely cover only the previous 1-4 weeks (e.g., CDI or CESD) are the only measures of depression. In addition, several potential moderators of depression (e.g., baseline levels of anxiety) were examined to determine if the initial episode of depressive disorder was predicted by the depressive symptoms or a comorbid diagnosis. 
Finally, the program included students from the full range of socio-economic status, strengthening its external validity for Portuguese youth.

The differences between those who participated only in the assessments as versus those who participated in the prevention program were still evident at the $\sim 24$-month follow-up period, indicating the sustained impact of the program among the at-risk youth who chose to participate in the program. Although not from an RCT, these data are consistent with the findings from Brent and colleagues (2015), who demonstrated that the individuals for whom the prevention program had been effective largely remained depression free for 3 years following the completion of the prevention program. Although the follow-up period was briefer (12 months), Arnarson and Craighead (2011) reported similar sustained effects of the same prevention program when it was implemented in Iceland. All these findings, taken together, support the conclusions of Werner-Seidler and colleagues (2017), who recommended that currently the most effective preventive interventions for depressive disorders are school-based indicated programs for youth at-risk for depressive disorders.

The presence of parental depression was evaluated in the current study, and the data indicated that parental depression at the time of baseline had no impact on the outcomes of this study. These data are inconsistent with the findings reported by Garber and colleagues (2009) and further substantiated on the same sample by Weersing and colleagues (2016). Perhaps the most parsimonious explanation of the different findings in the two studies stems from the different composition of the two samples studied. The current sample comprised only those youth at risk for depressive disorders, whereas the Garber and colleagues' sample included a large proportion of those who had already experienced a previous depression in addition to those who were at risk for their initial episode. It seems plausible that the presence of a depressed parent in the household of a youth, who had suffered a previous depression earlier in life, has a heightened impact on the ongoing life compared to those who have never experienced a depressive disorder and have a parent with depression. Thus, the earlier depression coupled with the presence of a depressed parent may have diminished the impact of the Garber and colleagues' (2009) program in preventing a depressive disorder. In contrast, the current prevention program could have had a preventive effect for those who have never had a depressive disorder even though there was a depressed parent present in the family. Given the inconsistent findings regarding the impact of parental depression on depression prevention programs, this is an important topic in need of further study. If at-risk youth (those with no prior depressive disorder) benefit whether or not there is a depressed parent, additional family intervention may not be required to prevent initial episodes of depression. However, it may be that for youth with a prior history of depression and a depressed parent, a more intensive, family-based prevention program such as the one developed by Craighead et al. (2017) may be needed.

Another interesting finding of the current study, consistent with the Icelandic findings (Arnarson \& Craighead, 2009), was that the depression prevention program's impact appeared to be specific to depressive disorders. In both studies there was minimal impact on other frequently co-occurring disorders (e.g., anxiety), which occurred equally frequently across the prevention program and assessment-only conditions. This held true even when the initial self-report levels of all measured cooccurring disorders, including baseline anxiety, were taken into account in the analyses. The focus of the intervention was on those behavioral and cognitive styles more specifically characteristic of depression rather than those that transcend depression and co-occurring disorders. Another factor contributing to the disorder-specific outcome may have been the participant selection process; participants were selected on the basis of a clinical interview and they were excluded from further participation in the intervention study if they met criteria for a previous or current mood disorders based on the K-SADS. The course of the disorder might have been different had the CDI alone been used to select participants because a high CDI score alone may be indicative of co-occurring anxiety and clinical mood disorders (Comer \& Kendall, 2005); these adolescents would not have been included in the current study because the information obtained during the clinical interview resulted in exclusion of those diagnosed with current or past mood disorders.

As indicated earlier, programs demonstrating the strongest preventive effects of depression have been indicated programs administered in the school setting. There are substantial arguments for school being the most ideal setting for preventive intervention programs (Werner-Seidler et al., 2017). Integration of assessment and identification of "at-risk" youth in the school combined with community health programs might provide for an effective program with more robust external validity and greater generalization to at-risk youth. Such a strategy would result in greater and more effective dissemination of evidence-based preventive programs. This implementation strategy may be especially pertinent for those countries that provide health services in central locations for all 
youth and in which all youth more regularly receive their health care at such locations, thereby reducing the possible stigmatization of participating in a depression prevention program.

\section{LIMITATIONS}

In order to mimic what would likely happen if a prevention program for depression were offered in a real-world school setting, we opted to allow youth identified as "at-risk" for depression to choose to participate in the program. Thus, the current study was not an RCT, which renders the results open to alternative interpretations. It is possible that those who chose to participate in the program were those who, even though at risk, were less likely to develop future episodes of depressive disorders. Even though the scientific interpretability of the cause of the group differences is limited by the design of this study, the results appear to be of practical utility for administrators and interventionists wishing to implement prevention program in schools.

A second limitation is the sample size, which limited the statistical power for data analyses. Despite a sample size of 168 in the project, significantly fewer of those at-risk adolescents who chose to participate in the prevention program compared to those who chose only to participate in assessments of the program suffered from a depressive disorder during the 24 months of the study. When considered as a whole, the outcomes were extremely similar to the results of the program when it had been tested in a randomized control trial (Arnarson \& Craighead, 2009, 2011). It is worth noting that even though the overall sample size was smaller than some prior prevention studies (e.g., Garber et al., 2009), the sample size of the specific groups in this study was not substantially smaller than those of preceding studies demonstrating the effectiveness of indicated programs (Werner-Seidler et al., 2017).

\section{CONCLUSION}

The current study employed a quasi-experimental design that compared those who chose to participate in a prevention of depression program to those equally at risk for depressive disorders but chose not to participate in the proffered program. At-risk Portuguese adolescents who chose to participate in the developmentally based cognitive behavioral program showed significantly fewer onsets of initial depressive disorders than those who chose not to participate in the program. The effects were consistent with those of prior studies employing RCTs of this and related programs. These studies provide encouraging data supporting generalization and further dissemination of indicated prevention program.

\section{Conflict of Interest Statement}

We wish to draw the attention of the Editor to the following facts which may be considered as potential conflicts of interest and to significant financial contributions to this work. EÖA and WEC are board members of Hugarheill ehf, an Icelandic company dedicated to the prevention of depression. WEC also receives book royalties from John Wiley \& Sons. His research is also supported by the NIH, the Mary and John Brock Foundation, and the Fuqua family foundations. He is a consultant to the George West Mental Health Foundation and the AIM for Mental Health Foundation.

We confirm that the manuscript has been read and approved by all named authors and that there are no other persons who satisfied the criteria for authorship but are not listed. We further confirm that the order of authors listed in the manuscript has been approved by all of us.

We confirm that we have given due consideration to the protection of intellectual property associated with this work and that there are no impediments to publication, including the timing of publication, with respect to intellectual property. In so doing we confirm that we have followed the regulations of our institutions concerning intellectual property.

We further confirm that any aspect of the work covered in this manuscript that has involved either experimental animals or human patients has been conducted with the ethical approval of all relevant bodies and that such approvals are acknowledged within the manuscript.

\section{References}

Arnarson, E. O., \& Craighead, W. E. (2009). Prevention of depression among Icelandic adolescents. Behaviour Research and Therapy, 47, 577e585. https://doi.org/10.1016/j.brat. 2009.03.011

Arnarson, E. O., \& Craighead, W. E. (2011). Prevention of depression among Icelandic adolescents: A 12-month follow-up. Behaviour Research and Therapy, 49(3), 170-174. https://doi.org/10.1016/j.brat.2010.12.008

Backenstrass, M., Frank, A., Joest, K., Hingmann, S., Mundt, C., \& Kronmüller, K. T. (2006). A comparative studyof nonspecific depressive symptoms and minor depression regarding functional impairment and associated characteristics in primary care. Comprehensive Psychiatry, 47(1), 35-41. https://doi.org/10.1016/j.comppsych.2005.04.007

Brent, D. A., Brunwasser, S. M., Hollon, S. D., Weersing, V. R., Clarke, G. N., Dickerson, J. F., ... Garber, J. (2015). Effect of a cognitive- behavioral prevention program on depression 6 years after implementation among at-risk adolescents: A randomized clinical trial. JAMA Psychiatry, 72(11), 1110-1118. https://doi. org/10.1001/jamapsychiatry.2015.1559

Calear, A. L., \& Christensen, H. (2010). Systematic review of school-based prevention and early intervention programs for depression. Journal of Adolescence, 33(3), 429-438. https://doi.org/10.1016/j.adolescence.2009.07.004

Casey, B. J., Jones, R. M., \& Hare, T. A. (2008). The adolescent brain. Annals of the New York Academy of Sciences, 1124, 111-126. https://doi.org/10.1196/annals.1440.010

Comer, J. S., \& Kendall, P. C. (2005). High-end specificity of the children's depression inventory in a sample of anxietydisordered youth. Depression and Anxiety, 22(1), 11-19. https://doi.org/10.1002/da.20059

Cox, D. R., \& Oakes, D. (1984). Analysis of survival data. London: Chapman \& Hall.

Craighead, W. E., Beardslee, W., \& Johnson, R. (2017). Prevention of Depression and bipolar disorder. In D. Evans 
et al. (Eds.), Treating and preventing adolescent mental health disorders ( $2^{\text {nd }}$ ed., pp. 69-88). New York: Oxford University Press.

Curtin, S. C., Warner, M., \& Hedegaard, H. (2016). Increase in suicide in the United States, 1999-2014. NCHS data brief, no 241. Hyattsville, MD: National Center for Health Statistics.

Dunlop, B. W., \& Mayberg, H. S. (2014). Neuroimaging-based biomarkers for treatment selection in major depressive disorder. Dialogues in Clinical Neuroscience, 16(4), 479.

Ferrari, A. J., Charlson, F. J., Norman, R. E., Patten, S. B., Freedman, G., Murray, C. J., Vos, T., \& Whiteford, H. A. (2013). Burden of depressive disorders by country, sex, age, and year: Findings from the global burden of disease study 2010. PLoS Medicine, 10, e1001547. https://doi.org/10. 1371/journal.pmed.1001547

Garber, J., Clarke, G. N., Weersing, V. R., Beardslee, W. R., Brent, D. A., Gladstone, T. R., ... Shamseddeen, W. (2009). Prevention of depression in at-risk adolescents: a randomized controlled trial. Journal of the American Medical Association, 301(21), 2215-2224. https://doi.org/10.1001/jama.2009.788

Giedd, J. N., Blumenthal, J., Jeffries, N. O., Castellanos, F. X., Liu, H., Zijdenbos, A., ... Rapoport, J. L. (1999). Brain development during childhood and adolescence: a longitudinal MRI study. Nature Neuroscience, 2(10), 861-863. https://doi.org/10.1038/13158

Hankin, B. L., Abramson, L. Y., Moffitt, T. E., Silva, P. A., McGee, R., \& Angell, K. E. (1998). Development of depression from preadolescence to young adulthood: Emerging gender differences in a 10-year longitudinal study. Journal of Abnormal Psychology, 107(1), 128-140. https://doi.org/10.1037/0021-843X.107.1.128

Jaycox, L. H., Stein, B. D., Paddock, S., Miles, J. N., Chandra, A., Meredith, L. S., . . Burnam, M. A. (2009). Impact of teen depression on academic, social, and physical functioning. Pediatrics, 124(4);e596-e605. https://doi.org/10.1542/ peds.2008-3348

Kaslow, N. J., Tannenbaum, R. L., \& Seligman, M. E. P. (1978). The KASTAN: A children's attributional style questionnaire. Unpublished manuscript, University of Pennsylvania, Philadelphia, PA.

Kaufman, J., Birmaher, B., Brent, D., Rao, U. M. A., Flynn, C., Moreci, P., ... Ryan, N. (1997). Schedule for affective disorders and schizophrenia for school-age children-present and lifetime version (K-SADS-PL): initial reliability and validity data. Journal of the American Academy of Child \& Adolescent Psychiatry, 36(7), 980-988. https://doi.org/10. 1097/00004583-199707000-00021

Keenan-Miller, D., Hammen, C. L., \& Brennan, P. A. (2007). Health outcomes related to early adolescent depression. Journal of Adolescent Health, 41(3), 256-262. https://doi. org/10.1016/j.jadohealth.2007.03.015

Keller, M. E. (1993). Adolescent-longitudinal interval follow-up evaluation (A-LIFE). Unpublished instrument. Available from M.E. Keller, Department of Psychiatry, Brown University School of Medicine, Providence, RI.

Keller, M. B., Lavori, P. W., Friedman, B., Nielsen, E., Endicott, J., McDonald-Scott, P., \& Andreasen, N. C. (1987). The Longitudinal Interval Follow-up Evaluation: a comprehensive method for assessing outcome in prospective longitudinal studies. Archives of General Psychiatry, 44(6), 540-548. https://doi.org/10.1001/archpsyc.1987.01800180050009

Kessler, R. C., Chiu, W. T., Demler, O., Merikangas, K. R., \& Walters, E. E. (2005). Prevalence, severity, and comorbidityof 12-month DSM-IV disorders in the national comorbidity survey replication. Archives of General Psychiatry, 62(6), 617-627. https://doi.org/10.1001/archpsyc.62.6.617
Klein, D. N., Glenn, C. R., Kosty, D. B., Seeley, J. R., Rohde, P., \& Lewinsohn, P. M. (2013). Predictors of first lifetime onset of major depressive disorder in young adulthood. Journal of Abnormal Psychology, 122(1), 1. https://doi.org/10.1037/ a0029567

Kovacs, M. (1992). Children's depression inventory. New York, NY: Multi-Health Systems, Inc.

Kovacs, M. (1985). The children's depression inventory (CDI). Psychopharmacological Bulletin, 21, 995-998.

Lewinsohn, P. M., Solomon, A., Seeley, J. R., \& Zeiss, A. (2000). Clinical implications of "subthreshold" depressive symptoms. Journal of Abnormal Psychology, 109(2), 345-351. https://doi.org/10.1037/0021-843X.109.2.345

March, J. S., Parker, J. D. A., Sullivan, K., Stallings, P., \& Conners, C. K. (1997). The Multidimensional Anxiety Scale for Children (MASC): Factor structure, reliability, and validity. Journal of the American Academy of Child and Adolescent Psychiatry, 36, 554-565. https://doi.org/10. 1097/00004583-199704000-00019

Marques, C., Matos, A. P., Salvador, M. C. (2018). Estudo psicométrico da K-SADS-PL em Portugal. [Psychometric study of the K-SADS-PL in Portugal.] Unpublished manuscript available from A.P.M

Marujo, H. M. A. (1994). Síndromas depressivos na infância e na adolescência [Depressive symptoms in childhood and adolescence] (Unpublished doctoral thesis). Faculdade de Psicologia e Ciências da Educação, Lisboa.

Matos, A. P., Costa, A., Martins, I., \& Antunes, J. (2017). Estudo psicométrico da A-Life em Portugal. [Psychometric study of the A-LIFE in Portugal.] Unpublished manuscript available from A. P. M.

McLeod, G. F. H., Horwood, L. J., \& Fergusson, D. M. (2016). Adolescent depression, adult mental health and psychosocial outcomes at 30 and 35 years. Psychological Medicine, 46(7), 401-412. https://doi.org/10.1017/S0033291715002950

Merry, S. N., Hetrick, S. E., Cox, G. R., Brudevold-Iverson, T., Bir, J. J., \& McDowell, H. (2011). Psychological and educational interventions for preventing depression in children and adolescents. Cochrane Database of Systematic Reviews, 12CD003380. https://doi.org/10.1002/14651858. CD003380.pub3

Nelson, J., Klumparendt, A., Doebler, P., \& Ehring, T. (2017). Childhood maltreatment and characteristics of adult depression: Meta-analysis. The British Journal of Psychiatry: the Journal of Mental Science, 210(2), 96-104. https://doi. org/10.1192/bjp.bp.115.180752

Nezu, A. M., Nezu, C. M., \& Perri, M. G. (1989). Wiley series on personality processes. Problem-solving therapy for depression: Theory, research, and clinical guidelines. Oxford, England: John Wiley \& Sons.

Pettit, J. W., Hartley, C., Lewinsohn, P. M., Seeley, J. R., \& Klein, D. N. (2013). Is liability to recurrent major depressive disorder present before first episode onset in adolescence or acquired after the initial episode? Journal of Abnormal Psychology, 122(2), 353-358. https://doi.org/10.1037/ a0032655

Salk, R. H., Hyde, J. S., \& Abramson, L. Y. (2017). Gender differences in depression in representative national samples: Meta-analyses of diagnoses and symptoms. Psychological Bulletin, 143(8), 783-822. https://doi.org/10.1037/ bul0000102

Salvador, C., Matos, A. P., Oliveira, S., March, J., Arnarson, E.Ö., ... Craighead, W. E. (2017). A escala multidimensional de ansiedade para crianças (MASC): Propriedades psicométricas e análise fatorial confirmatória numa amostra de adolescentes portugueses. [The Multidimensional Anxiety Scale for Children (MASC): Psychometric properties and confirmatory 
factor analysis in a sample of Portuguese adolescents.] Revista Iberoamericana de Diagnóstico y Evaluación -e Avaliação Psicológica, 45(3), 33-46. https://doi.org/10.21865/RIDEP45. 3.03

Schmaal, L., Hibar, D. P., Sämann, P. G., Hall, G. B., Baune, B. T., Jahanshad, N., ... Vernooij, M. W. (2017). Cortical abnormalities in adults and adolescents with major depression based on brain scans from 20 cohorts worldwide in the ENIGMA Major Depressive Disorder Working Group. Molecular Psychiatry, 22(6), 900-909. https://doi.org/10.1038/mp. 2016.60

Seligman, M. E. P., Peterson, C., Kaslow, N. J., Tanenbaum, R. L., Alloy, L. B., \& Abramson, L. Y. (1984). Attributional style and depressive symptoms among children. Journal of Abnormal Psychology, 93, 235e238. https://doi.org/10.1037/0021843X.93.2.235

Simões, M. R. (1995). Investigações no âmbito da Aferição Nacional do Teste das Matrizes Progressivas Coloridas de Raven (M.P.C.R) [Investigations in the context of the national standardization of the Raven Coloured Progressive Matrices test (RCPM)]. (Unpublished doctoral thesis). University of Coimbra, Portugal.

Smucker, M. R., Craighead, W. E., Craighead, L. W., \& Green, B. J. (1986). Normative and reliability data for the Children's Depression Inventory. Journal of Abnormal Child Psychology, 14(1), 25-39. https://doi.org/10.1007/BF00917219

Twenge, J. M., Joiner, T. E., Rogers, M. L., \& Martin, G. N. (2018). Increases in depressive symptoms, suicide-related outcomes, and suicide rates among US adolescents after 2010 and links to increased new media screen time. Clinical
Psychological Science, 6(1), 3-17. https://doi.org/10.1177/ 2167702617723376

van Zoonen, K., Buntrock, C., Ebert, D. D., Smit, F., Reynolds, C., Beekman, A. T. F., \& Cuijpers, P. (2014). Preventing the onset of major depressive disorder: A meta-analytic review of psychological interventions. International Journal of Epidemiology, 43, 318-329. https://doi.org/10.1093/ije/ dyt175

Weersing, V. R., Shamseddeen, W., Garber, J., Hollon, S. D., Clarke, G. N., Beardslee, W. R., ... Brent, D. A. (2016). Prevention of depression in at-risk adolescents: Predictors and moderators of acute effects. Journal of the American Academy of Child \& Adolescent Psychiatry, 55(3), 219-226. https://doi.org/10.1016/j.jaac.2015.12.015

Weinberger, A. H., Kashan, R. S., Shpigel, D. M., Esan, H., Taha, F., Lee, C. J., Funk, A. P., \& Goodwin, R. D. (2017). Depression and cigarette smoking behavior: A critical review of population-based studies. American Journal of Drug and Alcohol Abuse, 43(4), 416-431. https://doi.org/ 10.3109/00952990.2016.1171327

Werner-Seidler, A., Perry, Y., Calear, A. L., Newby, J. M., \& Christensen, H. (2017). School-based depression and anxiety prevention programs for young people: A systematic review and meta-analysis. Clinical Psychology Review, 51, 30-47. https://doi.org/10.1016/j.cpr.2016.10.005

Received: March 27, 2018

Accepted: November 27, 2018

Available online: $x x x x$ 